Releaned May 2000

ISSN0201-0147

Oysuppt in $\mathrm{xm}$

Sopelement har ubserihen fres if chary

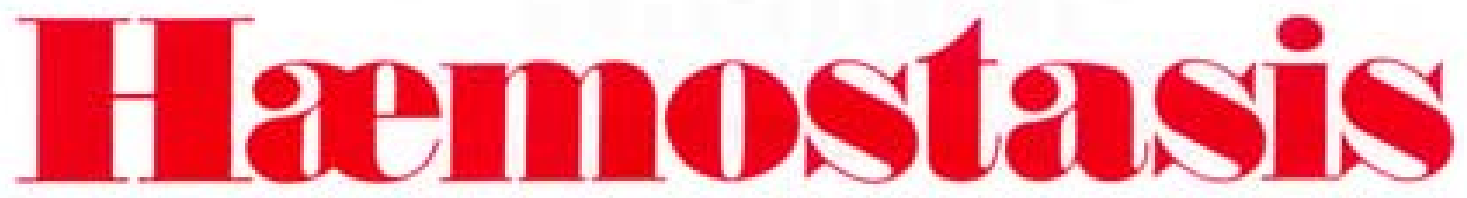

International Journal on

Haemostasis and Thrombosis Research

\title{
16th International Congress on Thrombosis
}

Porto, Portugal, May 5-8, 2000

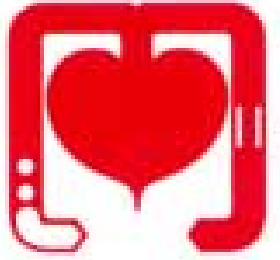

Abstracts

Guest Editors

M. Campos, Porto

L.M. Cunha-Ribeiro, Porto

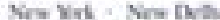
Hangled + Singapen Dare * sydw?

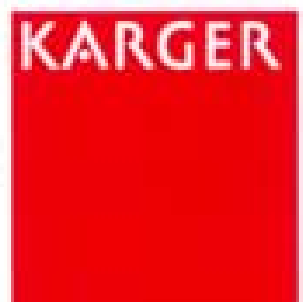


This issue contains the Abstracts of the

16th International Congress on Thrombosis

Porto, Portugal, May 5-8, 2000

and is not available online for technical reasons. 